\title{
Carbon price impacts on the Chinese tourism industry
}

\begin{abstract}
This study simulates the short-run effects of an Emissions Trading Scheme (ETS) and two auxiliary policies on the Chinese tourism industry. The results show that the ETS alone will increases energy prices and have significant adverse impacts on China's economy. The adverse impacts are relatively stronger on the energy sectors than they are on tourism. Two auxiliary policies a tourism subsidy and a reduced goods and services tax (GST) - are examined as policy options to soften the negative impacts of the ETS. Results show that the tourism-subsidy policy is more effective than the GST reduction policy.
\end{abstract}

\section{Keywords}

Carbon price, Chinese economy, tourism CGE modelling, tourism demand 


\section{Carbon price impacts on the Chinese tourism industry}

\section{Introduction}

Tourism is an important sector of the Chinese economy. Data from the China Tourism Institute (2018) show that in 2017 the tourism sector directly contributed 28.25 million jobs, equivalent to $3.64 \%$ of total employment and US $\$ 424.5$ billion or $3.29 \%$ of Chinese GDP. The total (direct and indirect) contribution of tourism to employment is 79.9 million jobs, or $10.29 \%$ of total employment. The total contribution to GDP was RMB 1349.3 billion, or $11.03 \%$. Inbound tourism is also an important source of foreign currency. In 2017, foreign visitors to China generated approximately US\$123.417 billion in earnings. Due to the importance of tourism, the Chinese government has made a substantial effort to improve the quality of tourism products, marketing tourism destinations and simplifying the tax return and visa application procedures for inbound visitors. However, the Chinese tourism industry is facing a new challenge of combating global warming and climate change.

In 2016, the United Nations General Assembly adopted the 2030 Agenda for Sustainable Development with 17 Global Sustainable Development Goals (SDGs) as the plan of action for global sustainable development (UNWTO, 2018). As the largest developing country in the world, China has become a primary focus of GHG emissions mitigation because of its status as the world's largest GHG emitter and the alarming speed of its emissions growth. Viewed from the perspective of its historical development, per capita emissions ( $\mathrm{CO}_{2}$-equivalent) in China increased $385.3 \%$ between 1990 and 2011 (EDGAR, 2017). It is projected that global carbon emissions would rise by more than 50\% if China's per capita GHG emissions increased to US levels, which are more than double those of China. Given China's share of global 
GHG emissions and the growth rate of its carbon emissions, most observers would contend that the effective slowing of human-induced climate change depends largely on China's emission growth trajectory. In response, China has assumed a stronger leadership role on climate change policy (Liu et al., 2015; Zhang, Harris \& Liu, 2018).

Alongside pressure from the international community, the escalating environmental problems from carbon emissions within China have prompted the Chinese Government to embark on a low-carbon and resource-efficient development pathway through a range of green development strategies. Among these strategies, the costeffective emissions reduction mechanism - an emission trading scheme (ETS) - is at the top of the agenda. After trials in seven pilot regions - Shenzhen, Shanghai, Beijing, Guangdong, Tianjin, Hubei and Chongqing - a nationwide ETS has been established and implemented in line with the Thirteenth Five-Year Plan period (20162020).

Akin with other destinations, the Chinese tourism industry is committed to combatting climate change caused by greenhouse gas (GHG) emissions. In light of this, changes to China's carbon policy warrant a thorough investigation of the potential impact of carbon pricing on the tourism sector. Many questions need to be answered: How would the carbon price affect the sector and to what degree? What could the government do to grow the industry while achieving its emission reduction target? How should the industry contribute to emission reduction in response to the new political imperatives? Although a number of studies have been conducted into the impact of carbon pricing on the Chinese economy (e.g. Zhang, 1998, 2011; Garbaccio 
et al, 1999; Cao et al, 2009; Qi et al, 2014; and Li et al, 2018), none has assessed the impacts on the tourism industry specifically. This article fills this gap.

This study simulates the short-run effects on the Chinese tourism industry of an Emissions Trading Scheme (ETS) and two additional policies to mitigate potential adverse effects. The simulation scenarios are designed to conform as closely as possible to the carbon emissions policy currently existing in China. In the 2009 Copenhagen Agreement, China pledged to reduce national emission intensity (total emissions as percentage of real GDP) by $40-45 \%$ from its 2005 level by 2020 . More recently, in the 2016 Paris Agreement, China committed itself to reducing the national emission intensity by 60-65\% from 2005 levels by 2030 . Data for emission reduction in recent years show that China is well on track to achieve these targets, with a $5 \%$ reduction per year on average. This observed annual reduction is used in this article to simulate the short-term effects of carbon reduction in China.

Since tourism is the focus of this article, and the tourism industry is likely to be adversely affected by the ETS, we consider a policy option directly related to tourism: a uniform subsidy to a small tourism-related group comprising transportation services, accommodation, restaurants and entertainment (including sightseeing). The funding for the subsidy comes from the permit revenue, modelled in a budget-neutral condition.

An alternative policy option of the so-called double dividend is also investigated for a comparison. This policy option asserts that when the carbon pricing revenue is used to reduce other taxes, such as the goods and services tax (GST), it not only brings benefits to the environment but also improves economic efficiency. We therefore present a scenario with a reduction in the GST tax across households, investors, 
government and tourists. To make the effect of this GST reduction policy and the tourism subsidy policy comparable, we assume an initial price of an emission permit set by the Chinese Government at the order of 11 RMB per tonne of carbon emissions (or a third of market permit price) so as to collect a revenue of 10 billion RMB. This can be used either as tourism subsidy or to offset the budget impact of the GSTreduction policy.

In summary, this study simulates three scenarios as follows:

- Scenario 1: a Chinese ETS to achieve a 5\% reduction in the national emission intensity, free emission permits allocated to sectors based on historical emission bases

- Scenario 2: a Chinese ETS to achieve a $5 \%$ reduction in national emission intensity as in scenario 1, with a mitigating policy of a subsidy of RMB 10 billion for core tourism sectors, including road transport, rail transport, air transport, water transport, post and storage, accommodation, restaurants and entertainment

- Scenario 3: a Chinese ETS to achieve a 5\% reduction in national emission intensity as in scenario 1, with an auxiliary policy of 10-billion GST reduction across all goods and services in the economy.

The remainder of the article is organised as follows. Section 2 reviews previous studies on carbon pricing with an emphasis on China and on tourism. Section 3 describes the database developed for the modelling task, the model structure and simulation design. Based on the modelling results, section 4 analyses the impact of a national ETS on the environment, tourism sectors and the Chinese economy. Section 5 summarises the findings and provides some policy suggestions. 


\section{Previous studies}

A large body of literature exists on carbon dioxide emissions and climate change using a general equilibrium approach. There are two main types of general equilibrium models: dynamic stochastic general equilibrium (DSGE) models and computable general equilibrium (CGE) models. Notable studies on carbon dioxide emissions using DSGE models include Bukowski and Kowal (2010), Dissou and Karnizova (2012), Khan. Knittel, Metaxoglou and Papineau (2015), Benavides, Gonzales, Diaz, Fuentes, Garcia, Plama-Behnke, and Ravizza (2015), Roach (2016), Niu, Yao, Shao, Li, and Wang (2018). Research on this topic using CGE models include Zhang, 1998a, 1998b, 2000, 2010, 2011; Cao, Ho \& Jorgenson, 2009; Devrajan et al., 2011; Li, Zhang \& Lu, 2018; Meng, Siriwardana \& McNeill, 2013; Nong, Meng \& Siriwardana, 2017; Wang, Wang \& Chen, 2009; Wei, Ni \& Du, 2011; Wissema \& Dellink, 2007.

Despite using different models with different assumptions and different destination contexts, these studies have consistently found that carbon-mitigation policies using carbon taxes or ETS does lead to reduced energy consumption and a decline in emission intensity per unit of GDP. The studies also show that carbon pricing results in higher production costs across most industries, reduced GDP or GNP, lower employment and reduced economic welfare.

A general conclusion is that aggregate gross output tends to decrease at an increasing rate as the carbon emissions target becomes more stringent. However, as expected, the adverse effects are vastly different among different industries. These adverse effects can partly be offset by measures such as subsidies and reductions in various direct and indirect taxes aimed to protect certain groups in the community or particular industry 
sectors, and such measures have been found to increase GDP growth (Garbaccio, Ho \& Jorgenson, 1999; Liang, Fan \& Wei, 2007; Qi et al., 2014; Zhang, 1998a; Zhou et al., 2011).

Tourism researchers have undertaken several studies of the impact of carbon pricing on tourism for various destinations. We will now briefly review the representative tourism studies.

From a theoretical point of view, Higham, Ellis and Maclaurin (2019) studied tourist aviation emissions. They used the decision-making theory and collective action theory to explain that encouraging voluntary action to reduce aviation emissions will not be successful. Then, they argued that participating in air travel regime is a social convention and transition from social conventions requires coordinated collective action. This conceptual work pointed to the importance of coordinated national or global policies in reducing carbon emissions.

Blanc and Winchester (2013) estimated the additional costs to airlines due to the European Union (EU) Emissions Trading System (ETS) on travel to 26 Caribbean destinations. The study used a downward-sloping demand function for air transportation services to generate the changes in tourism arrivals and airfares. With a proposed EU emission allowance price of $€ 10$, it was estimated that there is an average cost increase of US\$17 for a round trip from Europe to the Caribbean by indirect flights. For direct flights, the cost increase is averaged at US\$21. These additional costs were found to reduce tourism from the European Union to the Caribbean by between $1.4 \%$ and $2.0 \%$, and to reduce total tourist arrivals to the Caribbean by less than $0.4 \%$. 
In Australia, Dwyer, Forsyth and Spurr $(2012,2013)$ used a dynamic CGE model MMRF-GREEN and data from the Australian tourism satellite account to assess the potential economic impact of the Australian carbon tax on the tourism industry. They found that, compared with the projected baseline values over the period to 2020, most tourism industries in Australia would experience a mild contraction in output as a result $(-0.02 \%$ to $-1.48 \%)$. This contraction is in line with the slowing down of the economy as a whole. The reduction in tourism employment was found to be slightly larger than in other Australian industries. Meng and Pham (2017) used a Computable General Equilibrium model to gauge the economic and environmental impact of an Australian carbon tax, with an emphasis on the tourism industry. They found that a carbon tax of US\$23 per tonne would be very effective at achieving an emissions reduction, but that it would also cause a mild economic contraction. Regarding the tourism sector, nominal tourism expenditure shows an insignificantly positive growth under the carbon tax, but the real expenditure value shows a significant decline in both inbound and domestic tourism demand. The auxiliary policy - a household compensation package - stimulates domestic tourism considerably, but discourages inbound tourism further by contributing to a significant appreciation of the Australian dollar.

In China, Zhang and Zhang (2018a) used a CGE model and a social account matrix to simulate the impact of a carbon tax on tourism industries. Based on the simulation of three carbon tax rates of $10 \mathrm{RMB}$ per tonne, $50 \mathrm{RMB}$ per tonne and $90 \mathrm{RMB}$ per tonne, the authors suggested that while a carbon tax can effectively reduce tourismrelated carbon emissions, it will generally impose significant economic costs on the tourism industry - although the impacts on different tourism-related industries vary greatly. The article suggests that different carbon tax rates should be used for different 
tourism industries and that a carbon-tax compensation policy should be considered. Using the same model, Zhang and Zhang (2018b) studied energy consumption in the Chinese tourism industry, finding that fuel consumption, electricity consumption and energy intensity in the tourism industry would reduce mildly under a carbon tax.

Among the above studies, Zhang and Zhang (2018a, 2018b) are most relevant to this article, although there is no explicit tourism demand in their CGE model- the tourism industry is specified as a bundle of tourism-related sectors based on the definition by NBSPRC (2015) and UNWTO (2014). The simulation of emission policy - a carbon $\operatorname{tax}-$ is close to, but not consistent with, the ETS policy implemented in China. Our study overcomes this shortfall by explicitly developing a tourism industry so that the impacts of ETS on tourism can be assessed most accurately 


\section{Model, data and simulation design}

As stated earlier, there are two types of general equilibrium models. The DSGE model includes the stochastic trend in the model and thus reflects the uncertain nature of the real world. However, due to the probability approach used in simulation and estimation, the number of sectors in the model cannot be large nor can the mathematic functions used in the model be too complicated. Most DSGE models use CobbDouglas function and include only one to six industries. For example, there is only one sector in Roach (2016), two sectors in Niu, Yao, Shao, Li, and Wang (2018), three sectors in Benavides, Gonzales, Diaz, Fuentes, Garcia, Plama-Behnke, and Ravizza (2015), and six sectors in Dissou and Karnizova (2012). As a rare case, Bukowski and Kowal (2010) built a very large DSGE model of 11 sectors. On the other hand, CGE models cannot reflect the uncertainly in our daily life, but they can include more details of the economy and use more flexible functions to reflect the behaviour of economic agents. CGE models are now increasingly used in tourism economics analysis and policy formulation. CGE models can be applied to any combination of demand and supply-side shocks, under a range of alternative macroeconomic environments and policy scenarios. A strength of CGE analysis is that its assumptions can be varied and the sensitivity to them tested (Dwyer, 2015).

Due to the different features of the two types of models, DSGE models are commonly used for macroeconomic analysis and forecasting while CGE models are used for more detailed sectoral analysis. Since this study focuses on the detailed tourism and energy sectors, the CGE modelling approach is used since DSGE models are too aggregate for this type of research. 
To estimate the impacts of the ETS on tourism in China, we built a single-country CGE model for China (hereafter ORANI-CHN), based on the structure of the ORANI-G model (Horridge, 2000). To allow for the substitution between different fuel types and between energy and primary factors, we applied constant elasticity of substitution (CES) functions to combine energy inputs with primary factors. We also added different types of carbon emissions and an emission trading system. Inbound tourism and domestic tourism are modelled through downward-sloping demand functions. The database of the Chinese economy comprises 30 sectors and 30 commodities, one representative investor, one government, one representative household, one export demand and two types of tourism demands (domestic and inbound). As the ORANI-G model structure has been widely adopted and documented in many previous studies, we will briefly describe the modified model structure here.

The production nest is presented in Figure 1. At the top level, industries are assumed to adopt fixed ratios among all intermediate and primary inputs. At the bottom level, inputs are sourced from either domestic or imported sources, depending on the movements in relative prices. This substitution effect is realised by a CES function that allows the firms to minimise their production costs. The modelling of energy inputs deviates slightly from the conventional CGE structure. Non-energy inputs are grouped in the immediate input group while all energy inputs, including coal, oil, gas, electricity, and petrol \& coal products, are combined with capital to form a composite capital-energy input. This combination of energy and capital allows industries to change their production technology when energy prices change, reflecting the fact that expensive energy costs will prompt industries to adopt more energy-sufficient equipment in order to reduce energy consumption. The energy-capital bundle is combined with labour to form a composite primary-energy bundle. 
The functions for final demands are similar to those in the ORANI model (Dixon et al., 1982). Investment demand is a nested Leontief-CES function, household demand function is a linear expenditure system with CES nests. Export demand is a downward sloping demand of world prices of goods and services to reflect the assumption of small open economy. Government demand is indexed to household consumption. Inbound and domestic tourism demands are modelled through their responses to changes in the prices of tourism commodities.

The model captures carbon emissions in three different ways. First, stationary fuelcombustion emissions are tied with inputs (the amount of fuel used). The stationary emission intensity (the amount of emissions per dollar of inputs) is used as a coefficient to calculate stationary emissions based on the amount of inputs used. Second, the industry activity emissions (or process emissions) are calculated using industry output and the process emission intensity (emissions per unit of output) coefficient. Third, the consumption emissions by the household sector are estimated using the consumption emission intensity coefficient and the consumption level. In standard simulations of the model, all three types of emission intensities are assumed fixed to reflect unchanged technology.

\section{$<$ Insert FIG 1 about here $>$}

The emissions trading scheme is modelled through government-issued emission permits. The government can issue the permit for free, or charge an arbitrary initial price. All sectors are required to submit their permits to match their yearly emissions with the number of permits tied to the emission reduction target of the government. The permits are allocated to sectors based on their historical emission base. Each sector can purchase or sell its permits depending on its emission levels. If a sector's 
emissions are greater than its emission allowance, it must buy permits from other sectors, and vice versa.

The main data used for the modelling include input-output data, carbon-emission data, tourism expenditure data and various behaviour parameters. The input-output data used in this study are from the 2015 Chinese Input-Output Tables, published by the National Bureau of Statistics of the People's Republic of China (NBSPRC, 2017). Since the 2015 database has 42 aggregate sectors with only 3 tourism related sectors, it is supplemented by relativities of the highly disaggregated 2012 Input-Output database containing 139 sectors, published by the NBSPRC (2015).

The Chinese carbon emission data are based mainly on existing studies. Shan and colleagues (2018) estimate that total carbon emissions in 2015 were 9779.5 megatonnes, including 685.6 megatonnes of process emissions from cement and 9093.5 megatonnes stationary emissions from the use of fuels such as coal, oil and gas. While this total emission estimate is broadly similar to other sources, it did not take into account the process emissions from sectors other than cement, and seems to have been under-estimated. For example, the estimated process emissions for cement production alone in 2012 by CDIAC (2013) and EDGAR (2016) were approximately 1.1 gigatonnes and 0.88 gigatonnes respectively. NCCC (2012) shows that the Chinese process emissions from agricultural activities was as high as 0.82 gigatonnes. Liu (2015) shows that there are significant process emissions from other production activities, such as those for glass, soda ash, ammonia, calcium carbide and alumina.

Given the discrepancy of the process emissions, we have incorporated all various sources to derive a new level of process emission for this research. For cement alone, 
process emissions are based on EDGAR (2016) - a mid-point value among three estimates. Process emissions for agriculture (NCCC, 2012) and other sectors (Liu et al., 2015) were also incorporated. The total emissions for 2015 amounted to 11.231 gigatonnes.

Detailed tourism demand data for China are hard to obtain because the Chinese government publishes the data for aggregate tourist arrivals and tourism expenditure only. The State Council of China (2016) reveals additional information for 2015 inbound and domestic tourism in China separately. For the inbound segment, the number of tourist arrivals was 134 million visitors, generating US\$113.65 billion of tourist receipts (equivalent to RMB 738.73 based on the exchange rate in 2015). For the domestic component, the number of visitors was estimate to be four billion, generating RMB 3420 billion in tourism receipts.

The total tourism expenditure needs to be disaggregated to different goods and services. For inbound tourism, the disaggregation is done according to the 2016 foreign tourism expenditure in '2018 China Statistical Yearbook' published by National Bureau of Statistics of China (2018, p592). The Chinese government does not publish domestic tourism expenditure each year. The latest data on this is the detailed domestic tourism spending pattern by China National Administration of Tourism (2007). However, these data are relatively old compared with our base year 2015. We updated this expenditure pattern based on 2012 urban household survey data by National Bureau of Statistics of China (2012) and tourism survey data provided by Beijing Tourism Development Committee (Xing \& Yu, 2018) and the People's Government of Hainan Province (2012). National Bureau of Statistics of China (2012, p83) provides useful data on cultural and creational services. The other two surveys show an increase in spending on air travel and shopping, and a decrease 
in water transportation and postage service, compared with the 2007 national domestic tourism expenditure pattern. We updated the national pattern to reflect these trends. The tourism shopping pattern was supplemented by the findings of Chang, Wang and Dong (2018), who analysed the data on online tourism commodity shopping in Beijing. The shopping items are classified into three main types: food products (dried fruits, alcohol, tea, meat products, pastry, etc.); gifts (porcelain, textile and leather products); and printing products (books, notebooks, diaries, wall planners).

Most behavioural parameters in the ORANI-CHN model are adopted from GTAPE (Burniaux \& Truong, 2002), including export demand elasticity, all Armington substitution elasticities for goods and services and labour types, and particularly the substitution among energy inputs (coal, oil, gas, electricity, and petrol and coal products). The substitution between composite energy and capital is generally considered to be very small, with values commonly found to range between 0.1 and 0.6 . They are set at 0.4 in this article.

The elasticity for tourism demand is a key parameter for this study. Song, Gartner and Tasci (2012) estimated the price elasticities of inbound tourism demand in China from ten major origins, finding an average of -0.802 . We adopt this elasticity value for inbound tourism in our model. For domestic tourism, Yang, Liu and Qi (2014) estimated a price elasticity of -0.428 for tourists from urban areas and -0.307 for tourists from rural areas. Since the majority of domestic tourists in China come from urban areas, where economic development is growing strongly in relative terms, we use -0.4 in our model for domestic tourism demand. The demand elasticity is applied directly to goods and services identified in the tourist expenditure pattern. The value of -0.4 is applied broadly to all goods and services, while demands for shopping and hotels by visitors are treated more 
specifically. Given the higher flexibility of shopping by visitors, we doubled the elasticity for tourism shopping for visitors in both segments - that is, 1.604 for inbound tourism shopping and 0.800 for domestic tourism shopping. On the other hand, since it can be argued that expenditure on restaurants and accommodation is relatively inflexible, we applied just half the value, meaning 0.401 for inbound visitors and 0.2 for domestic visitors.

As explained in section 1, we simulate the short-run effect of three scenarios: (1) ETS only, (2) ETS plus tourism subsidy of 10 billion RMB; and (3) ETS plus GST reduction of 10 billion RMB. We focus on the short-run effect for three reasons. First, it takes time to invest in, and implement, emission reduction technology, so the short-run effect is generally greater than the long-run effect. The tourism industry needs short-run information to be prepared. Second, the current world climate change policy is uncertain. Any change in climate policy or emission reduction targets may make the long-run effect less useful. Finally, the energy saving and storage technology (e.g. renewable energy and battery technology) is on the brink of breakthrough. The advent of new technology in the energy area will reduce the emission reduction cost substantially, so the long-run projection in this environment is less reliable. The simulations were performed under a short-run macroeconomic closure, meaning fixed real wages and capital stocks but free movements of labour and rates of return to capital. The exchange rate was set exogenously at zero to reflect the fixed exchange regime in China. 


\section{Results and analysis}

The aforementioned three scenarios are simulated using GEMPACK (Harrison et al., 2014) and sensitivity tests are performed using the systematic sensitivity analysis built into the software. The sensitivity tests show that, overall, the simulation results are only mildly sensitive to the elasticity values used. However, the environmental results (i.e. emission reductions) are moderately sensitive to the elasticity values for different types of fuels, while the tourism demands are moderately sensitive to tourism price elasticities. Unless specified, impacts in this article are measured as percentage deviation of policy scenarios from the baseline case scenario where there is no carbon policy.

\subsection{Environmental, tourism and macroeconomic effects}

The aggregate simulation results are shown in Table 1, listing environmental effects, tourism effects, macroeconomic effects, and the effects on international trade. Results for the environmental effects in the first panel are reported in the form of absolute change for carbon emission levels, and percentage change for energy price and energy usage.

\section{$<$ Insert Table 1 about here $>$}

In each scenario, an ETS aiming at a 5\% reduction of national emission intensity reduces Chinese carbon emissions by slightly more than 580 megatonnes. The total reduction in carbon emissions comprises three parts: reduction in stationary emissions due to stationary combustion of fuels; reduction in process emissions in industrial production; and reduction in consumption emissions by households. 
The total emission reduction exceeds the targeted 5\% reduction of national emission intensity as a percentage of GDP. This is because the real GDP value decreases in all scenarios: an ETS adds costs to production and depresses consumption so that the economy will scale back. The emission reduction rate in scenarios 2 and 3 is slightly smaller than in scenario 1 because the effects of the subsidy policy (scenario 2) and the GST-reduction policy (scenario 3) actually stimulate production and consumption to offset the adverse impacts of the implementation of the ETS, resulting in a smaller reduction in real GDP (see macroeconomic effects in Table 1). Given the different size of real GDP change, the same target of reduction in national emission intensity leads to slightly different percentage changes in $\mathrm{CO}_{2}$ emissions.

To achieve the $5 \%$ reduction in national emission intensity, the market price for ETS permits must reach about 34-35 RMB/tonne. The permit price is marginally higher in scenario 3 and moderately higher in scenario 2. Because of the stimulus effects of tourism subsidy and GST-reduction policies in scenarios 2 and 3, emission levels tend to increase; however, the target of reduction in national emission intensity is the same for all scenarios, so a higher carbon price is required to offset this effect. The last two rows in panel 1 show the percentage change in energy prices and usage. As expected, the energy price increases by more than $3.8 \%$, which reduces energy demand by between 1.81 and $1.95 \%$. The decrease in energy usage in scenario 2 is smallest because the subsidy policy encourages the use of transportation services, which are relatively energy intensive.

The second panel shows that the ETS significantly affects both inbound and domestic tourism. In scenario 1 , the tourism price indexes increase by $0.29 \%$ for inbound tourism and $0.26 \%$ for domestic tourism. The increases in the tourism price indexes in 
scenarios 2 and 3 are relatively smaller under the influence of the tourism subsidy and the GST reduction policies. Comparing all scenarios, the tourism price index increases the least in scenario 2 , as the subsidy is targeted directly at tourism goods and services, effectively offsetting the upward pressure on tourism prices caused by the ETS.

Facing higher prices for tourism goods and services, the real tourism demand decreases significantly under the ETS. This means that tourism arrivals and the length of stay will be significantly below the present tourism growth trend in China. An interesting aspect of the results is that, in scenarios 1 and 3, real inbound tourism decreases more than the real domestic tourism demand, while the price index increases less for inbound tourists. This may be due largely to the fact that price elasticity for inbound visitors $(0.8)$ is more sensitive than that of the domestic visitors (0.4) because foreigners are prone to variation of real exchange rate. The last two rows in the second panel show the nominal value of tourism demand. Since the size of positive percentage change in the tourism price index is greater than the size of negative percentage change in real tourism demand, the nominal tourism demand increases in all scenarios.

The third panel comprises effects at the macroeconomic level. The first three rows show the changes in price indexes. The GDP price index increases in all scenarios due to the increase in the production cost introduced by the ETS. The increases in GDP price index are smaller in scenarios 2 and 3 due to the expansionary nature of the policies in these scenarios. The consumer price index (CPI) also increases in all scenarios, but the size of the increase is only about half of that for the GDP deflator. This indicates that the CPI basket is much less emissions intensive than the GDP 
basket. The capital rental price decreases substantially in all scenarios. This result is understandable considering the higher production cost and thus lower profit generated by firms under the ETS.

The significant increases in the GDP deflator and in the CPI have a dominant effect on nominal values, with the nominal GDP and nominal household consumption increasing significantly in all scenarios; however, the real economy contracts. In scenarios 1 to 3 , the real GDP decreases by $0.25 \%, 0.19 \%$ and $0.24 \%$, while the real household consumption decreases by $0.04 \%, 0.01 \%$, and $0.03 \%$, respectively. The significant reduction in GDP results from the increased production cost and thus represents the cost of emission reduction to the economy. Using the real GDP as a criterion, we can conclude that tourism-subsidy policy is much more effective and beneficial than the economy-wide GST-reduction policy.

The last panel of Table 1 displays the effects on international trade. To reflect the reality, we used a fixed exchange rate regime for our simulations. Although the nominal exchange rate is fixed, the real exchange rate can change, based on domestic prices. Since the ETS causes substantial increase in price levels in China, Chinese goods become more expensive for foreigners, so foreign currency effectively depreciates - that is, the Chinese currency appreciates in real terms. The changes in the real value of RMB are shown in the first row. They are quite similar to the changes in the GDP deflator because the latter is the main contributor. The second row shows the changes in terms of trade. Since it is measured by the ratio of the price of exports to the price of imports, its percentage change is the different between percentage changes in the exports price and the imports price. Since the model used for this study is a single-country model, import prices are assumed to be unchanged. 
Consequently, the increase in terms of trade in Table 1 also indicates the percentage change in exports prices.

With an increase in real price levels in China, it is expected that real imports will increase while real exports will decrease since imports are relatively cheaper for residents and exports are relatively more expensive for foreigners. Consequently, the real balance of trade will worsen. This explains the decreased contribution of the real balance of trade to GDP in the third row in the last panel. The relatively greater reduction in scenario 1 is due mainly to the higher price pressure on the economy in this scenario. Since the world price of imports to China is set exogenous in the simulations, changes in nominal and real imports are identical. The change in nominal exports is positive because the increase in export prices is greater than the decrease in real exports. This means that although exports volume can fall under the ETS, export revenue can increase.

\subsection{Sectoral effects}

Table 2 lists the percentage changes in sectoral output and in output prices following the ETS. Since tourism sectors are of major concern, they are listed in the first panel. The core tourism sectors, which are subsidised in scenario 2, are marked with an asterix. The core tourism sectors comprise traditional tourism sectors such as accommodation, restaurants and entertainment, as well as various transportation sectors and post and storage sector on which tourists spend a significant amount of their budget. Here the entertainment sector includes various entities involved in travel booking, touring, cultural activities, sports events, and tourism attraction ticketing. Since these activities are closely related and each has a relatively small output, we lump them together as one sector. 


\section{$<$ Insert Table 2 about here $>$}

Table 2 shows that the emission-reduction policy will cause the output of all industries to contract across all scenarios. Tourism sectors are affected only moderately, with output reduction ranging from $0.21 \%$ to $0.64 \%$ in scenario 1 . The main transportation sectors (road, rail, air and water) experience relatively greater output reduction due to their energy intensive nature. For non-tourism sectors, coal and gas experience substantial reductions in output, with a decrease of $7.21 \%$ for coal and $10.44 \%$ for gas, respectively. The large output decrease in the coal sector is expected because of its highest emission intensity. The large output reduction in the gas sector is somewhat surprising because the emission intensity of gas is not very high. One reason may be the high process emission in the gas sector due to fugitive emissions. Another reason may be the relatively small base size of the gas sector in China. Other sectors of high emission/energy intensity - for example, the oil sector, the petrol and coal products sector, the electricity sector, the gas supply sector, the other mining sector, the other manufacturing sector, and the other transport sector also experience substantial reductions in output. The remaining sectors are affected only mildly.

The pattern of impacts at the sectoral level is similar across all three scenarios but to a lesser extent in scenarios 2 and 3, due to the redistribution effect of the ETS revenue. Output reductions are less in scenario 2 than in scenario 3, as the stimulus of the injected revenue in the second scenario is on specific goods and services with less carbon content. This demonstrates the effectiveness of the subsidy policy. The effects of tourism-subsidy policy also extend to some non-tourism sectors - for example, the output of the agriculture sector decreases only by $0.29 \%$ in scenario 2 compared with 
a reduction of $0.41 \%$ in scenario 3 . The petrol and coal products sector, the other manufacturing sector, and the other transport sector, also have significantly less output reduction in scenario 2 . These results indicate that these sectors have a strong linkage with the core tourism sectors.

The right panel of Table 2 shows a general upward pressure on prices for most commodities as a result of the introduction of the ETS. In scenario 1, significant price hikes occur to electricity $(2.90 \%)$, petrol and coal products $(2.37 \%)$, coal $(2.21 \%)$ and gas supply (1.58\%). The rise of commodity prices results from the high production costs resulting from the ETS. These industries are able to pass on part of their increased production costs to their customers, in the form of increased commodity prices. Some commodity prices do, however, decrease - for example, in scenario 1 the price of finance decreases by $0.74 \%$, oil by $0.54 \%$, gas by $3.39 \%$, real estate by $0.09 \%$ and trade service by $0.04 \%$. The fall in commodity prices reflects the decrease in demand for domestic goods. As most commodities become more expensive, the increased price level reduces the real income of households, so total demand decreases. The relatively cheaper imports also play an important role. Industries associated with falling commodity prices come under considerable pressure. The low prices of their products lead to reduced revenue while their production costs increase, so their profit margin will reduce considerably or even totally disappear.

Compared with scenario 1, the other scenarios exert less upward pressure on prices due to the counter-effects of the two auxiliary policies. The subsidy policy reduces the prices of tourism goods directly and the indiscriminating GST-reduction policy reduces the prices of all commodities across the board. Price increases in scenario 2 are generally not as high as those in scenario 3. This further shows that a tourism 
subsidy can generate an economy-wide impact through intersectoral linkage and through the price mechanism.

Table 3 displays the emissions reduction and energy usage under the three different scenarios. The left panel shows the emission reductions across all sectors, while the right panel demonstrates the percentage change in energy use. The changes in the volumes of emission and in energy uses vary considerably across the sectors.

\section{$<$ Insert Table 3 about here $>$}

The contribution of tourism-related sectors to the emission-reduction scheme are modest (see top half of Table 3), as these industries are not carbon-intensive. The tourism-related industries that reduce emissions significantly through the ETS include wood and print (4.64 megatonnes), food and tobacco (2.52 megatonnes) and textile and leather (2.28 mega tonnes). Reductions in emissions from road transport and rail transport are 0.75 megatonnes and 0.58 megatonnes respectively. The emissions cuts by other tourism sectors are negligible.

For the non-tourism related industries, five sectors are estimated to contribute the majority of emission reduction in the ETS. Coal could cut emissions by 158.56 megatonnes, other manufacture by 171.74 megatonnes, electricity by 146.14 megatonnes, petrol and coal products by 67.74 megatonnes, and gas supply by 16.93 megatonnes. The second tier of non-tourism contributors includes agriculture (3.66 megatonnes), gas (2.89 megatonnes), other mining (2.55 megatonnes), construction (1.27 mega tonnes) and other services (1.71 megatonnes). The remaining sectors cut emissions by less than 1 megatonne. 
The right panel of Table 3 shows that energy usage decreases significantly for all sectors. Although the percentage change ranges from $-13.68 \%$ to $-0.47 \%$, the vast majority of sectors cut energy usage by $1-3 \%$. Energy usage reduction is achieved through the price mechanism: the ETS increases the cost of energy production, so the energy price increases. Faced with higher energy prices, firms will reduce energy usage in order to reduce their production costs. Since energy usage is linked to carbon emissions through energy prices, the significant reduction of energy usage by all sectors indicates that all sectors share the burden of emissions reduction and thus contribute significantly but indirectly to emissions reduction under the ETS.

Some sectors show a high correlation between emissions and energy usage. For example, coal is estimated to reduce its emissions by 158.56 megatonnes, while its energy usage is also estimated to decrease by $9.75 \%$. The high reductions in energy usage for the food and tobacco sector and the textile and leather sector are also consistent with their high emissions reductions among the tourism sectors. The correlation between emissions and energy usage does not, however, hold for all sectors. A number of sectors including gas supply, trade service, accommodation, entertainment, oil, other transport, ICT and finance, show high levels of energy reduction but low levels of emission reduction.

The reduction in energy usage is generally smaller in scenarios 2 and 3 than in scenario 1 . This indicates that both the tourism-subsidy policy and the GST-reduction policy tend to lead to higher energy usage. Some sectors, including coal, gas, construction, education and health, experience a greater energy reduction in scenario 2 and/or scenario 3 compared with scenario 1 . These results are consistent with the high emission reductions by these sectors under the tourism subsidy or the 
GST reduction polies. This implies that the impact of higher carbon prices in scenarios 2 and 3 may have dominant effects for these sectors.

\section{Conclusions}

We have developed a CGE model to simulate the short-run effect of a Chinese national ETS under different policy scenarios. The simulation results show that, under an ETS aimed at reducing Chinese national emission intensity by $5 \%$, the market price for emission permits would be about $34 \mathrm{RMB}$ per tonne of $\mathrm{CO}_{2}$. The total emission reduction is about 588 megatonnes, or $5.24 \%$ of the total emission base. The impact of the ETS on tourism is less severe than for most of other sectors in the Chinese economy. This conclusion is different from the conclusion by Zhang and Zhang (2018a) that a carbon price will have a significant impact on the Chinese tourism industry. The difference may stem from the different definition of tourism. In this article, tourism is defined by tourism demand, but in Zhang and Zhang's (2018a) study, tourism consists of 14 tourism-related industries. Since these tourism-related sectors cater to both tourism demand and non-tourism demand, the impact of a carbon price on these sectors can differ from its impact on the tourism market. 
Comparing the macroeconomic results for scenarios 2 and 3 with those in scenario 1 , we found that both a tourism-subsidy policy and a GST-reduction policy can mitigate the adverse impacts of the ETS on the domestic economy by redistributing the permit revenue back to the economy. However, judged by real GDP, real household consumption and aggregate employment, the tourism-subsidy policy is much more effective than the GST-reduction policy.

The difference in efficiency may come from the nature of the two policies. On one hand, the broad GST-reduction policy induces households and tourists to increase consumption on all goods and services, including emission-intensive goods such as petrol and coal products. As such, the policy will work to offset - at least to some extent - the effect of the ETS in emission reduction. On the other hand, the focussed tourism-subsidy policy mainly reduces the prices of tourism goods, which are relatively less emission-intensive. Although the double-dividend policy is sound in principle, its actual effect is only marginal due to its general approach to stimulating final consumption. The targeted-subsidy policy - tourism in this case - can help to soften the adverse impact of the emission-reduction policy on the economy significantly.

This conclusion is confirmed by sectoral-level results. The GST-reduction policy improved the performance of all sectors quite evenly due to the non-discriminatory nature of this policy. The tourism-subsidy policy greatly benefits both the core tourism sectors that receive the subsidy and tourism-related sectors that do not receive the subsidy. This indicates strong sectoral linkages among tourism sectors. Interestingly, the non-tourism sectors generally also perform better under the tourism- 
subsidy policy than under the GST-reduction policy. This suggests that the tourism sectors are well integrated into the wider economy.

The study has several policy implications. First, since an ETS is an effective and efficient way to reduce emissions, the government should commit to this policy. Although the policy will cause a significant reduction in economic activity, this drawback will be overcome in time by a better quality of environment in the future. The negative impacts of the ETS on the tourism sectors are relatively mild, so tourism sectors should welcome and actively engage in this policy. Second, both tourismsubsidy policy and the GST-reduction policy will improve the economy, while achieving the same emissions intensity-reduction target, implying that the government should charge some initial price for emission permits and use the revenue to fund auxiliary environmental policies. Third, while results support the double-dividend hypothesis in principle, the performance of the tourism-subsidy policy is much better than that of the GST-reduction policy. Thus, the government should consider a tourism-subsidy policy instead of a non-discriminatory GST-reduction policy. Considering the effects of different levels of subsidies or determining optimal subsidy would be an interesting topic for further research.

The Paris Agreement recognises a core role for carbon pricing to decarbonise all industries, providing the foundation for facilitating international cooperation to achieve this. As one of the main economic sectors worldwide, tourism must play its role in this essential transition (UNWTO, 2018). Decarbonising the tourism industry must be part of wider policy initiatives, both nationally and internationally. Although this study focused on China, the approach can be used in other destinations globally to inform policy-makers about the effects of ETS schemes on the wider economy and 
the tourism industry specifically, as well as the effectiveness and efficiency of different auxiliary policies to address imbalances.

The limitations of this study are related to the scope of modelling. The study concerns only the short-run effects due to uncertainties in world climate change policies and the development of technologies on renewable energy and energy saving and storage. If major emitters in the world recognize the importance of reducing carbon emissions and agree on carbon policies, and/or if there is a breakthrough in energy related technologies, a large amount of investment would flow to renewable energy industry and emission reduction can be achieved with much less negative impacts on the economy. In this case, a long run simulation would then be warranted. Another limitation is that the study does not capture the positive effects of the carbon price on the tourism industry resulting from mitigating the adverse impacts of climate change on tourism attractions and resources. Estimating the tourism impacts of climate change due to carbon emissions is a difficult but important task, and a much needed area for future research. Finally, the study does not consider the proportion of Chinese outbound tourism expenditure that was spent within China, before and after the trips (e.g. domestic airfares and other incidental expenses). Although it is a small proportion, it does contribute to the total tourism emissions in the country. Future research could consider the effects of outbound tourism and the extent to which it affects our findings.

\section{References}


AEC Group. 2013. "Carbon tax impacts on the Australian accommodation industry". Retrieved from https://www.aecgroupltd.com/files/images/taa_carbon_tax_document2.pdf.

Benavides, C., L. Gonzales, M. Diaz, R. Fuentes, G. Garcia, R. Plama-Behnke, and G. Ravizza. 2015. "The Impact of a Carbon Tax on the Chilean Electricity Generation Sector", Energies, 8: 2674-2700.

Blanc, É., \& N. Winchester. 2013. “The impact of the EU emissions trading system on air passenger arrivals in the Caribbean". Journal of Travel Research, 52(3), $353-363$.

Bukowski, M. and P. Kowal, 2010. "Large Scale Multi-sector DSGE Model as a Climate Policy Assessment Tool”, IBS working paper 03/3010, Institute for structural research.

Burniaux, J. \& T. P. Truong, 2002. "GTAP-E: An energy-environmental version of the GTAP Model”. GTAP Technical Paper No. 16. Retrieved from https://www.gtap.agecon.purdue.edu/resources/download/1203.pdf.

Cao, J., M. Ho, \& D. Jorgenson, 2009. "The local and global benefit of green tax policies in China". Review of Environmental Economic and Policy, 3(2), 189208.

CDIAC [Carbon Dioxide Information Analysis Center]. 2013. “Global, regional and national fossil-fuel $\mathrm{CO}_{2}$ emissions". Retrieved from http://cdiac.ornl.gov/trends/emis/overview-2010.html.

Chang, X., B. Wang, \& Y. Dong, 2018. “A study on Beijing online tourism commodities based on Taobao data". In 2018 annual report on Beijing tourism development by Beijing Tourism Association. Beijing: Social Sciences Academic Press of China. 
China National Tourism Administration, 2007, "Sample Survey of Domestic Tourism in China 2007”, Beijing: China Tourism Press

China Tourism Institute. 2018. China tourism development Report 2018. Retrieved from https://www.pinchain.com/article/170100.

Devrajan, S., D. Go, S. Robinson, \& K. Thierfelder, 2011. “Tax Policy to Reduce Carbon Emissions in a Distorted Economy: Illustrations from a South Africa CGE Model", The B.E. Journal of Economic Analysis and Policy, 11(1):1-22.

Dissou, Y. \& L. Karnizova, 2012. "Emission Cap or Emission Tax? A Multi-sector Emissions Cap or Emissions Tax? A Multi-sector Business Cycle Analysis”, Working Papers 1210E, University of Ottawa, Department of Economics.

Dixon, P. B., B. R. Parmenter, J. Sutton, \& D. P. Vincent, 1982. "ORANI: Multisectoral model of the Australian economy”. Amsterdam: North-Holland.

Dwyer, L., P. Forsyth, \& R. Spurr, 2012. "Wither Australian tourism? Implications of the carbon tax". Journal of Hospitality and Tourism Management, 19, 1-16.

Dwyer, L., P. Forsyth, R. Spurr, \& S. Hoque, 2013. "Economic impacts of a carbon tax on the Australian tourism industry". Journal of Travel Research, 52(2), $143-155$.

Dwyer, L. 2015. “Computable General Equilibrium Modelling for Tourism Policy Inputs and Outputs", Statistics and TSA Issues Paper Series, UNWTO, Madrid EDGAR. 2016. “Trends in global $\mathrm{CO}_{2}$ emissions 2016 report”. Retrieved from http://edgar.jrc.ec.europa.eu/news_docs/jrc-2016-trends-in-global-co2emissions-2016-report-103425.pdf.

EDGAR. 2017. "Fossil $\mathrm{CO}_{2} \& \mathrm{HG}$ emissions of all world countries". Retrieved from http://edgar.jrc.ec.europa.eu/overview.php?v=CO2andGHG1970$2016 \& d s t=\mathrm{CO} 2 \mathrm{pc}$. 
Garbaccio, R., M. Ho, \& D. Jorgenson, 1999. "Controlling carbon emissions in China". Environment and Development Economics, 4: 495-518.

Harrison, J., J. M. Horridge, M. Jerie, \& K. R. Pearson, 2014. GEMPACK manual. Retrieved from https://www.copsmodels.com/gpdoc.htm

Higham, J., E. Ellis, and J. Maclaurin, 2019. “Tourist Aviation Emissions: A Problem of Collective Action”, Journal of Travel Research, 58(4):535-548

Horridge, M. 2000. “ORANI-G: A general equilibrium model of the Australian economy”. Melbourne: Centre of Policy Studies/IMPACT Centre, Monash University.

Khan, H. C. Knittel, K. Metaxoglou, and M. Papineau, 2015. "How do Carbon Emissions Respond to Business-cycle Shocks”, CEEPR WP 2015-011, MIT Center for Energy and Environmental Policy Research.

Li, W., Y. W Zhang, \& C. Lu, 2018. "The impact on electric power industry under the implementation of national carbon trading market in China: A dynamic CGE analysis". Journal of Cleaner Production, 200: 511-523.

Liang, Q., Y.Fan, \& Y. Wei, 2007. “Carbon taxation policy in China: How to protect energy- and trade-intensive sectors”. Journal of Policy Modelling, 29: 311-333.

Liu, L., C. Chen, Y. Zhao, \& E. Zhao, 2015. “China's carbon-emissions trading: Overview, challenges and future". Renewable and Sustainable Energy Reviews, 49, 254-266.

Mayor, K., \& R. Tol, 2007. "The impact of the UK aviation tax on carbon dioxide emissions and visitor numbers". Transport Policy, 14(6), 507-513. 
Mayor, K., \& R. Tol. 2010. "The impact of European climate change regulations on international tourist markets". Transportation Research Part D, 15, 26-36.

Meng, X., M. Siriwardana, \& J. McNeill, 2013. "The environmental and economic impact of the carbon tax in Australia". Environmental and Resource Economics, 54(3): $313-332$.

Meng, S., \& T. Pham, 2017. The impact of the Australian carbon tax on the tourism industry. Tourism Economics, 23(3): 506-522.

National Bureau of Statistics of China. 2012. "China Urban Life and Price Yearbook 2012”, Beijing: China Statistics Press.

National Bureau of Statistics of China. 2015. "Chinese input-output tables 2012”. Beijing: China Statistics Press.

National Bureau of Statistics of China. 2017. “Chinese input-output tables 2015”. Beijing: China Statistics Press. Retrieved from http://data.stats.gov.cn/ifnormal.htm? $\mathrm{u}=/$ files/html/quickSearch/trcc/trcc01.html $\& \mathrm{~h}=740$.

National Bureau of Statistics China. 2018. “China Statistical Yearbook 2018”, China Statistics Press.

NCCC [National Coordination Committee on Climate Change]. 2012. "Second National Communication on Climate Change of the People's Republic of China”. Beijing: China Planning Press.

Niu, T., X. Yao, S. Shao, D. Li, and W. Wang, 2018. "Environmental Tax Shocks and Carbon Emissions: An estimated DSGE model", Structural Change and Economic Dynamics, 47: 9-17.

Nong, D., S. Meng, \& M. Siriwardana, 2017. “An assessment of a proposed ETS in Australia by using the MONASH-Green model". Energy Policy, 108: 281-291. 
People's Government of Hainan Province. 2012. "Hainan tourism: From scale to efficiency". Retrieved from http://www.hainan.gov.cn/hn/zwgk/tjdc/hntj/dcfx/201203/t20120312_770742.ht $\mathrm{ml}$.

Qi, T., N. Winchester, V. Karplus, \& X. Zhang, 2014. "Will economic restructuring in China reduce trade-embodied $\mathrm{CO}_{2}$ emissions?" Energy Economics, 42: 204-212.

Roach, T. 2016. Optimal Dynamic Carbon Taxation over the Business Cycle, https://pdfs.semanticscholar.org/0e05/faef195d9b06126b81029d85d12d003193ab.pdf

Shan, Y., D. Guan, H. Zheng, J. Ou, Y. Li, J. Meng, Z. Mi, Z. Liu, \& Q. Zhang, 2018. “Data Descriptor: China $\mathrm{CO}_{2}$ emission accounts 1997-2015”. Scientific Data. Retrieved from https://www.nature.com/articles/sdata2017201.

Song, H., W. Gartner, \& A. Tasci, 2012. "Visa restrictions and their adverse economic and marketing implications - evidence from China”. Tourism Management, 33: 397-412.

State Council of China. 2016. Thirteenth five-year plan of tourism development. Retrieved from http://www.gov.cn/zhengce/content/201612/26/content_5152993.htm.

Tol, R. 2007. "The impact of a carbon tax on international tourism". Transportation Research Part D, 12: 129-142.

UNWTO. 2014. International recommendations for tourism statistics 2008 compilation guide - Unedited draft version. Retrieved from http://unstats.un.org/unsd/statcom/doc14/BG-Tourism.pdf

UNWTO. 2018. Tourism and the Sustainable Development Goals: Journey to 2030. https://www.e-unwto.org/doi/pdf/10.18111/9789284419401 
Wang, K., C. Wang, \& J. Chen, 2009. “Analysis of the economic impact of different Chinese climate policy options based on a CGE model incorporating endogenous technological change”. Energy Policy, 8: 2930-2940.

Wei, C., J. Ni, \& L. Du, 2011. "Regional allocation of carbon dioxide abatement in China”. China Economic Review, 23(3): 552-565.

Wissema, W., \& R. Dellink, 2007. "AGE analysis of the impact of a carbon energy tax on the Irish economy”. Ecological Economics, 61: 671-683.

Xing, H., \& H. Yu, 2018. “Business model innovation of Beijing's traditional travel agencies in the sharing economy". In 2018 annual report on Beijing tourism development by Beijing Tourism Association. Beijing: Social Sciences Academic Press of China.

Yang, Y., Z-H Liu, \& Q. Qi, 2014. "Domestic tourism demand of urban and rural residents in China: Does relative income matter?" Tourism Management, 40:193-202.

Zhang, J., \& Y. Zhang, 2018a. “Carbon tax, tourism $\mathrm{CO}_{2}$ emissions and economic welfare". Annals of Tourism Research, 69(C): 18-30.

Zhang, J., \& Y. Zhang, 2018b. "Exploring the impacts of carbon tax on tourismrelated energy consumption in China". Sustainable Development. DOI: $10.1002 / \mathrm{sd} .1900$.

Zhang, Y., J.Harris, \& J. Li, 2018. "China moves forward with carbon markets". Carbon, 2(8), 2-8.

Zhang, Z. 1998a. "Macro-economic and sectoral effects of carbon taxes: A general equilibrium analysis for China”. Economic Systems Research, 10(2): 135-159. 
Zhang, Z. 1998b. "Macroeconomic effects of $\mathrm{CO}_{2}$ emission limits: A computable general equilibrium analysis for China”. Journal of Policy Modeling, 20(2):213-250.

Zhang, Z. 2000. "Can China afford to commit itself to an emissions cap? An economic and political analysis". Energy Economics, 22, 587-614.

Zhang, Z. 2010. “The US proposed carbon tariffs and China's responses". Energy Policy, 38(5): 2168-2170.

Zhang, Z. 2011. Energy and environmental policy in China: Towards a low carbon economy. Cheltenham: Edward Elgar.

Zhou, S., M. Shi, N. Li, \& Y. Yuan, 2011. "Impacts of carbon tax policy on $\mathrm{CO}_{2}$ mitigation and economic growth in China". Advances in Climate Change Research, 2(3), 124-133. 
Figure 1: The structure of production functions

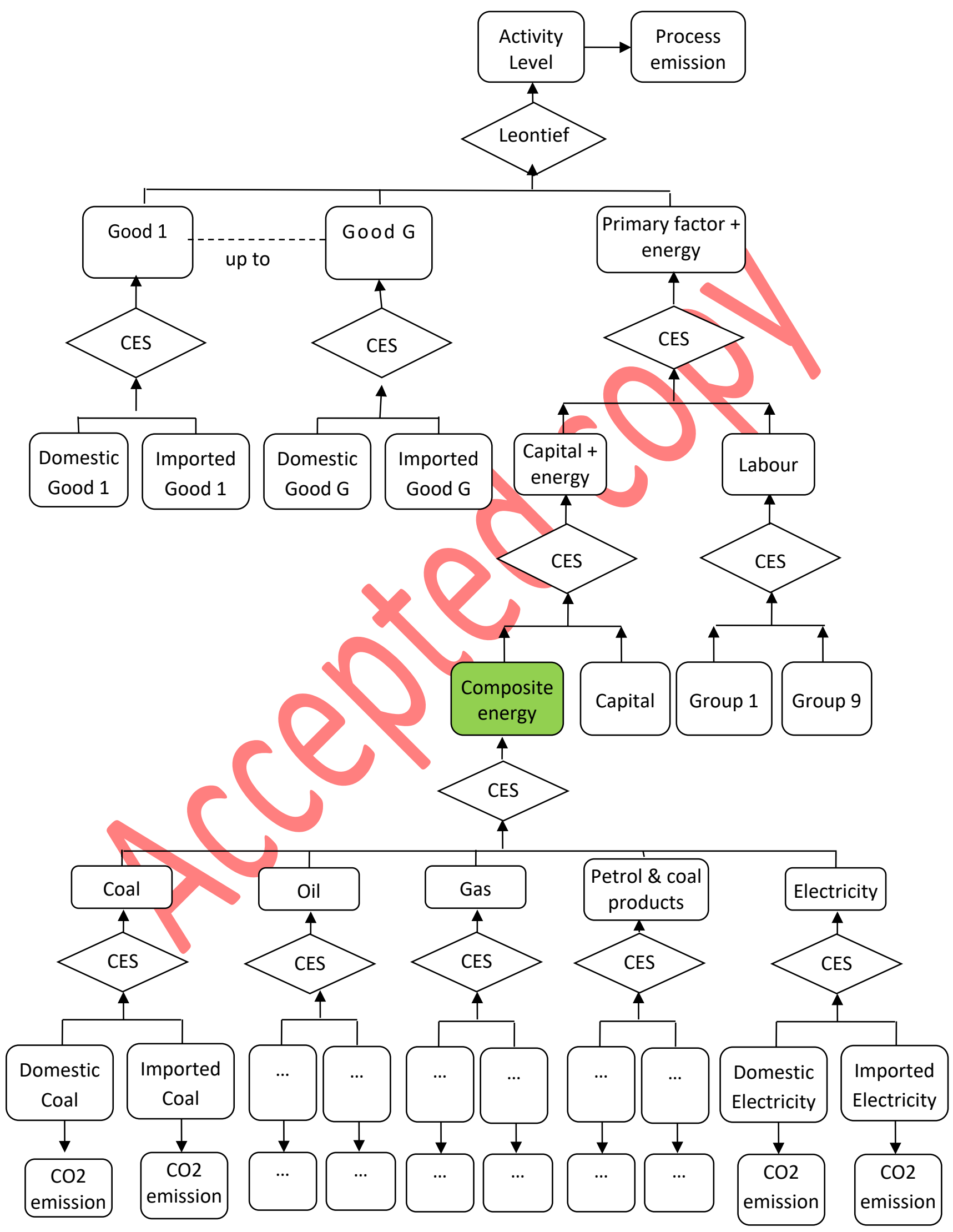


Table 1: The environmental, tourism, macroeconomic and trade effects of the ETS

\begin{tabular}{|c|c|c|c|}
\hline Type of effect & \begin{tabular}{|} 
Scenario 1: \\
$-5 \%$ cuts \\
in $\mathrm{CO} 2$ \\
intensity
\end{tabular} & $\begin{array}{l}\text { Scenario 2: } \\
\text { Scenario } 1 \\
\text { plus tourism } \\
\text { subsidy of } 10 \\
\text { billion RMB }\end{array}$ & $\begin{array}{l}\text { Scenario 3: } \\
\text { Scenario 1 } \\
\text { plus GST } \\
\text { reduction of } \\
10 \text { billion } \\
\text { RMB }\end{array}$ \\
\hline Environmental effec & & & \\
\hline Total reduction in $\mathrm{CO}_{2}$ emissions (Mt) & -588.22 & -581.46 & -587.15 \\
\hline Reduction in stationary emissions (Mt) & -562.61 & -558.52 & -561.87 \\
\hline Reduction in process emissions (Mt) & -23.85 & -21.14 & -23.52 \\
\hline Reduction in household emission (Mt) & -1.77 & -1.80 & -1.76 \\
\hline Percentage change in $\mathrm{CO}_{2}$ emission & -5.24 & -5.18 & -5.23 \\
\hline Market price for ETS permits (RMB/tonne) & 33.95 & 35.14 & 33.98 \\
\hline Percentage change in energy rental price & 3.84 & 6 & 3.83 \\
\hline Percentage change in energy usage & -1.95 & & 94 \\
\hline Tourism effects ( & & & \\
\hline Inbound tourism pri & 0.29 & 0.14 & 0.24 \\
\hline Domestic tourism price index & 0.26 & 0.10 & 0.21 \\
\hline Real inbound touris & .22 & -0.10 & -0.18 \\
\hline Real domestic tourism & -0.10 & -0.04 & -0.08 \\
\hline Nominal inbound tourism & 0.07 & 0.04 & 0.06 \\
\hline Nominal domestic tourism & 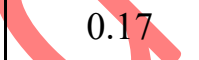 & 0.06 & 0.14 \\
\hline Macroeconomi & & & \\
\hline GDP price index & 0.49 & 0.31 & 0.46 \\
\hline Consumer price index & 0.28 & 0.14 & 0.24 \\
\hline Capital rental price & -0.58 & -0.36 & -0.57 \\
\hline Nominal GDP & 0.24 & 0.12 & 0.22 \\
\hline Nominal total hou & 0.24 & 0.13 & 0.20 \\
\hline Real GDP & -0.25 & -0.19 & -0.24 \\
\hline Real household cc & -0.04 & -0.01 & -0.03 \\
\hline Aggregate employment & -0.37 & -0.23 & -0.35 \\
\hline Trade effects: & & & \\
\hline Percentage change in Real value of RMB & -0.49 & -0.30 & -0.46 \\
\hline Percentage change in terms of trade & 0.53 & 0.37 & 0.52 \\
\hline Change of balance of trade as \% of GDP & -0.18 & -0.14 & -0.17 \\
\hline Percentage change in real imports & 1.48 & 1.20 & 1.45 \\
\hline Percentage change in real exports & 0.26 & 0.18 & 0.26 \\
\hline Percentage change in nominal imports & 1.48 & 1.20 & 1.45 \\
\hline Percentage change in nominal exports & -0.26 & -0.18 & -0.26 \\
\hline
\end{tabular}

Note: units of nominal changes are specified, others are shown as percentage changes. 
Table 2: Percentage change in sectoral output and price under the ETS in China

\begin{tabular}{|l|r|r|r|r|r|r|}
\hline \multicolumn{1}{|c|}{ Sector } & \multicolumn{3}{|c|}{ Output } & \multicolumn{3}{|c|}{ Price } \\
\cline { 2 - 7 } & Scenario 1 & Scenario 2 & Scenario 3 & Scenario 1 & Scenario 2 & Scenario 3 \\
\hline Food \& tobacco & -0.28 & -0.18 & -0.26 & 0.35 & 0.15 & 0.33 \\
Textile \& leather & -0.30 & -0.18 & -0.29 & 0.34 & 0.12 & 0.32 \\
Wood \& print & -0.43 & -0.31 & -0.41 & 0.41 & 0.21 & 0.39 \\
Trade service & -0.29 & -0.21 & -0.28 & -0.04 & -0.16 & -0.06 \\
Road transport* & -0.43 & -0.34 & -0.42 & 0.38 & 0.22 & 0.36 \\
Rail transport* & -0.45 & -0.35 & -0.43 & 0.36 & 0.16 & 0.34 \\
Air transport* & -0.40 & -0.30 & -0.38 & 0.53 & 0.39 & 0.51 \\
Water transport* & -0.64 & -0.51 & -0.62 & 0.44 & 0.32 & 0.42 \\
Post \& storage* & -0.34 & -0.27 & -0.33 & 0.36 & 0.20 & 0.34 \\
Accommodation* & -0.31 & -0.20 & -0.29 & 0.26 & 0.08 & 0.23 \\
Restaurant* & -0.26 & -0.17 & -0.24 & 0.27 & 0.06 & 0.25 \\
Entertainment* & -0.21 & -0.12 & -0.19 & 0.18 & 0.01 & 0.16 \\
& & & & & & \\
Agriculture & -0.43 & -0.29 & -0.41 & 0.62 & 0.41 & 0.59 \\
Coal & -7.21 & -7.18 & -7.20 & 2.21 & 2.11 & 2.20 \\
Oil & -1.25 & -1.13 & -1.24 & -0.54 & -0.56 & -0.55 \\
Gas & -10.44 & -10.53 & -10.42 & -3.39 & -3.52 & -3.39 \\
Other mining & -0.79 & -0.65 & -0.78 & 0.61 & 0.48 & 0.60 \\
Petrol \& coal products & -1.48 & -1.35 & -1.47 & 2.37 & 2.34 & 2.36 \\
Other manufacture & -0.63 & -0.50 & -0.62 & 0.74 & 0.57 & 0.72 \\
Electricity & -1.23 & -1.06 & -1.22 & 2.90 & 2.87 & 2.89 \\
Gas supply & -0.40 & -0.34 & -0.39 & 1.58 & 1.51 & 1.57 \\
Water supply & -0.36 & -0.30 & -0.35 & 0.70 & 0.55 & 0.68 \\
Construction & -0.02 & -0.02 & -0.02 & 0.54 & 0.32 & 0.52 \\
Other transport & -0.91 & -0.79 & -0.90 & 0.39 & 0.21 & 0.37 \\
ICT & -0.15 & -0.10 & -0.14 & 0.11 & -0.02 & 0.10 \\
Finance & -0.42 & -0.35 & -0.41 & -0.74 & -0.77 & -0.75 \\
Real estate & -0.27 & -0.21 & -0.26 & -0.09 & -0.18 & -0.10 \\
Education & -0.08 & -0.03 & -0.06 & 0.26 & 0.07 & 0.23 \\
Health & -0.08 & -0.04 & -0.07 & 0.46 & 0.25 & 0.44 \\
Other service & -0.19 & -0.14 & -0.18 & 0.31 & 0.12 & 0.29 \\
\hline
\end{tabular}


Table 3: The sectoral emissions and energy usage under the ETS in China

\begin{tabular}{|l|r|r|r|r|r|r|}
\hline \multicolumn{1}{|c|}{ Sector } & \multicolumn{2}{|c|}{ Emission cuts (Mt) } & \multicolumn{2}{c|}{ \% change in energy use } \\
\cline { 2 - 6 } & Scenario 1 & Scenario 2 & Scenario 3 & Scenario 1 & Scenario 2 & Scenario 3 \\
\hline Food \& tobacco & -2.52 & -2.52 & -2.52 & -2.04 & -1.88 & -2.02 \\
Textile \& leather & -2.28 & -2.29 & -2.27 & -1.56 & -1.42 & -1.55 \\
Wood \& print & -4.64 & -4.64 & -4.64 & -2.16 & -2.03 & -2.16 \\
Trade service & -0.04 & -0.04 & -0.04 & -1.69 & -1.60 & -1.68 \\
Road transport* & -0.75 & -0.75 & -0.75 & -1.24 & -1.15 & -1.23 \\
Rail transport* & -0.58 & -0.59 & -0.58 & -1.50 & -1.39 & -1.49 \\
Air transport* & -0.08 & -0.08 & -0.08 & -1.19 & -1.09 & -1.18 \\
Water transport* & -0.17 & -0.16 & -0.17 & -1.50 & -1.36 & -1.49 \\
Post \& storage* & -0.23 & -0.23 & -0.23 & -1.21 & -1.14 & -1.20 \\
Accommodation* & -0.03 & -0.03 & -0.03 & -1.46 & -1.36 & -1.45 \\
Restaurant* & -0.07 & -0.07 & -0.07 & -1.04 & -0.98 & -1.03 \\
Entertainment* & -0.10 & -0.10 & -0.10 & -1.50 & -1.41 & -1.49 \\
& & & & & & \\
Agriculture & -3.66 & -2.55 & -3.48 & -1.55 & -1.46 & -1.54 \\
Coal & -158.56 & -159.26 & -158.52 & -9.75 & -9.77 & -9.74 \\
Oil & -0.16 & -0.15 & -0.16 & -3.12 & -2.91 & -3.12 \\
Gas & -2.89 & -2.91 & -2.89 & -13.68 & -13.80 & -13.66 \\
Other mining & -2.55 & -2.53 & -2.54 & -1.63 & -1.45 & -1.62 \\
Petrol \& coal products & -67.74 & -65.51 & -67.55 & -1.68 & -1.55 & -1.67 \\
Other manufacture & -171.74 & -169.45 & -171.38 & -1.77 & -1.61 & -1.76 \\
Electricity & -146.14 & -144.09 & -145.91 & -1.51 & -1.30 & -1.50 \\
Gas supply & -16.93 & -17.03 & -16.89 & -0.47 & -0.40 & -0.45 \\
Water supply & -0.03 & -0.03 & -0.03 & -1.21 & -1.14 & -1.20 \\
Construction & -1.27 & -1.31 & -1.28 & -1.04 & -1.08 & -1.05 \\
Other transport & -0.01 & -0.01 & -0.01 & -1.90 & -1.78 & -1.90 \\
ICT & 0.00 & 0.00 & 0.00 & -1.55 & -1.48 & -1.55 \\
Finance & -0.01 & -0.01 & -0.01 & -2.31 & -2.16 & -2.29 \\
Real estate & -0.21 & -0.20 & -0.21 & -1.67 & -1.56 & -1.66 \\
Education & -0.56 & -0.58 & -0.56 & -1.48 & -1.50 & -1.49 \\
Health & -0.79 & -0.80 & -0.79 & -1.80 & -1.83 & -1.81 \\
Other service & -1.71 & -1.74 & -1.71 & -1.36 & -1.35 & -1.36 \\
\hline
\end{tabular}

